\title{
Consciência fonológica de vinte e três disléxicos falantes do português
}

\author{
Phonological awareness in twenty-three Portuguese dyslexic speakers
}

\author{
Vera Pedreira dos Santos Pepe* \\ Universidade Estadual de Feira de Santana \\ Feira de Santana, Bahia, Brasil
}

\begin{abstract}
Resumo: O presente estudo, com recorte transversal, investiga o desempenho de sujeitos disléxicos em tarefas de consciência fonológica, a partir do enfoque teórico do déficit de processamento fonológico da dislexia. A amostra é composta por 23 sujeitos disléxicos, falantes do português brasileiro, nas faixas etárias entre 8;0 e 14;11. O instrumento utilizado para a coleta de dados foi o CONFIAS, Consciência Fonológica: Instrumento de Avaliação Sequencial (MOOJEN et al, 2003), que avalia a consciência fonológica nos níveis da sílaba e do fonema. Os resultados mostraram que, no nível da sílaba, a tarefa mais difícil foi a Produção de Rima; no nível do fonema, foi a Transposição. Os resultados evidenciaram, também, o uso de estratégias linguísticas, a exemplo de Associação Fonológica, Associação Semântica, entre outras.
\end{abstract}

Palavras-chave: Consciência fonológica. Dislexia. Estratégias linguísticas

Abstract: This cross-sectional study reports an investigation on dyslexic subjects performance in phonological awareness tasks and it is based on dyslexia phonological deficit approach. Data were collected of 23 dyslexic subjects, all Brazilian Portuguese speakers, aged 8 to 14;11 years old. For this, it was used a phonological awareness test named CONFIAS, Phonological Awareness: Sequencial Evaluation Assessment (MOOJEN et al, 2003), which evaluates phonological awareness in the syllable level and in the phoneme level. Results show that in the syllable level, Rhyme Production was the most difficult task; in the phoneme level, it was Transposition. Results also point out the use of some linguistic strategies, such as Phonological Association, Semantic Association and others.

Keywords: Phonological awareness, dyslexia, linguistic strategies.

\section{INTRODUÇÃO}

A dislexia do desenvolvimento é um transtorno de leitura (e de escrita), de origem constitucional, caracterizado por dificuldades que o indivíduo possui para decodificar palavras com precisão e/ou fluência, em virtude de um déficit no processamento fonológico. Este, por sua vez, envolve operações mentais referentes a informações sobre o componente fonológico da linguagem e, embora atue em um nível cognitivo, apresenta impactos no comportamento linguístico do indivíduo.

As dificuldades para decodificar palavras acometem crianças com inteligência dentro dos padrões de normalidade, sem deficiências sensoriais e com oportunidades educacionais adequadas. Por conta disso, essas dificuldades são consideradas inesperadas em relação à idade, a outras habilidades cognitivas e ao grau de escolaridade dos indivíduos afetados. Comprometimento no crescimento do vocabulário e problemas com a compreensão da leitura podem se manifestar como consequências secundárias (HEILMAN, 1996; ANNALS OF DYSLEXIA, 2003).

* Professora da Universidade Estadual de Feira de Santana, doutora em Letras e Linguística. Email: verapepe2010@gmail.com. 
A literatura aponta uma estreita relação entre dislexia e consciência fonológica, no sentido de que, em geral, sujeitos disléxicos apresentam dificuldades na execução de tarefas metalinguísticas (BRYANT e BRADLEY, 1978; STANOVICH e SIEGEL, 1994; SNOWLING, 2004, entre outros), em virtude de um déficit no processamento fonológico.

A consciência fonológica é definida como a habilidade metalinguística de refletir sobre os sons da fala e de manipulá-los, contemplando, assim, unidades como sílabas, rimas, fonemas, entre outras. Exemplificam consciência fonológica: capacidade do indivíduo para segmentar, juntar, transpor sílabas e fonemas em palavras; capacidade para identificar sílabas e fonemas iniciais ou em posição final de palavra; capacidade para identificar e produzir rimas, entre outras (MOOJEN et alii, 2003). Como pode ser visto, a consciência fonológica refere-se à estrutura da palavra, e não ao seu significado, ou seja, ela é a habilidade linguística que o indivíduo possui para prestar atenção às formas das palavras, às suas estruturas. Quanto mais precisas as representações fonológicas em um nível cognitivo, mais facilmente as tarefas de consciência fonológica são executadas.

A literatura também aborda a existência de uma relação entre consciência fonológica e a aprendizagem da leitura e da escrita e, dentro dessa perspectiva, surgem três concepções acerca dessa relação: de causa, de efeito e de reciprocidade. Na relação de causa, a consciência fonológica é vista como um pré-requisito para a aprendizagem da leitura e da escrita; na relação de efeito, ela é encarada como uma consequência dessa aprendizagem; e na relação de reciprocidade, a consciência fonológica favorece a aprendizagem da leitura e da escrita, assim como essa aprendizagem aprimora o desenvolvimento da consciência fonológica.

O presente estudo, a partir do enfoque teórico do déficit de processamento fonológico na dislexia, tem por objetivo geral investigar o comportamento linguístico de disléxicos na execução de tarefas de consciência fonológica, e por objetivos específicos descrever e analisar o desempenho linguístico de sujeitos disléxicos em tarefas de consciência fonológica nos níveis da sílaba e do fonema, elaborar uma escala capaz de refletir os diferentes graus de dificuldade enfrentados pelos sujeitos na execução das tarefas metalinguísticas e identificar estratégias linguísticas adotadas pelos sujeitos para solucionar as tarefas propostas.

A amostra do estudo, de desenho transversal, foi constituída de 23 sujeitos disléxicos, 09 meninas e 14 meninos, falantes do português brasileiro, alunos da rede privada de ensino, e nas faixas etárias entre 8;0 e 14;11. O teste utilizado para a coleta de dados foi o CONFIAS, Consciência Fonológica: Instrumento de Avaliação Seqüencial (MOOJEN et alii, 2003), cujo objetivo é avaliar a consciência fonológica nos níveis da sílaba $(\mathrm{S})$ e do fonema $(\mathrm{F})$, mediante a aplicação de tarefas orais. Vale salientar que os dados caracterizam-se como secundários, tendo em vista que haviam sido coletados, durante a elaboração da tese de doutorado da autora (PEPE, 2010).

\section{CONSIDERAÇÕES SOBRE CONSCIÊNCIA FONOLÓGICA E DISLEXIA}

Nesta seção, serão abordados os seguintes tópicos: consciência linguística e consciência fonológica, consciência fonológica e a aprendizagem de leitura e da escrita, dislexia e consciência fonológica.

\subsection{CONSCIÊNCIA LINGUÍSTICA E CONSCIÊNCIA FONOLÓGICA}

Durante a aquisição inicial da linguagem pela criança, observa-se o uso dessa capacidade linguística como instrumento de expressão e de compreensão de intenções, de sentimentos, de significados. Nessa fase de socialização, em geral, a criança utiliza a linguagem com função 
comunicativa, sem prestar muita atenção às formas das palavras, afinal o foco é o conteúdo da situação dialógica, a brincadeira, a interação com o outro. Durante esse período, a aquisição dessa competência linguística ocorre naturalmente, tendo como resultado o domínio de regras gramaticais internalizadas e utilizadas de forma não consciente, mas que orientam o desempenho linguístico espontâneo da criança.

As brincadeiras com rimas elucidam essa circunstância, tendo em vista que, nos jogos de rimar, é frequente encontrarmos crianças inventando rimas para não saírem perdedoras da disputa com seus pares. Freitas (2004), inclusive, chama a atenção para o fato de que a rima representa um nível de conhecimento fonológico elementar, afinal, desde cedo, faz parte da rotina da criança e está presente em músicas, brincadeiras, livros infantis, entre outros tantos materiais. Vale lembrar que, conquanto sejam capazes de perceber alguns elementos linguísticos, as crianças ainda não são capazes de explicitar essas percepções.

Com o passar do tempo, porém, essa situação vai mudando e a criança começa a refletir e a manipular elementos linguísticos, em seus diferentes níveis, de forma consciente, o que significa dizer que ela passa a lançar mão da chamada consciência linguística (CARVALHO, 2003). A língua, portanto, passa a ser tomada como objeto de reflexão e análise.

Há alguns anos, tive o prazer de presenciar uma situação de florescimento da consciência linguística em meus filhos. A minha mais velha, certa vez, virou-se para mim e disse: Mãe, antes en falava sadaleira, mas agora eu falo saladeira, não é? O meu caçula, referindo-se ao meu local de trabalho comentou: Eu falava UESF, mas agora en já falo UEFS né, mãe?

É curioso notar que ambos demonstram já ter consciência do antes (sadaleira, UESF) e do depois (saladeira, UEFS), ou seja, tomam a língua como objeto de análise, focalizando a atenção nas suas formas.

O termo consciência linguística, portanto, indica a capacidade que o ser humano possui para refletir e para manipular, conscientemente, as formas da sua língua em seus diferentes níveis: sintático, morfológico, semântico, pragmático e fonológico. A consciência linguística no nível fonológico é denominada consciência fonológica.

Assim, consciência fonológica é a habilidade para prestar atenção à forma das palavras, assim como a habilidade para perceber que, no continuum da fala, as palavras, embora pareçam, não são blocos inteiros, mas formas passíveis de serem segmentadas em unidades menores (sílabas e fonemas). Em outras palavras, a consciência fonológica caracteriza-se como uma habilidade metafonológica que o indivíduo possui para refletir sobre os sons da fala e para manipulá-los, cognitivamente, de forma consciente, envolvendo, assim, consciência de sílabas, rimas, fonemas, entre outras unidades intrassilábicas.

Exemplificam habilidades de consciência fonológica a capacidade do indivíduo para identificar e produzir rimas; transpor, segmentar, unir, excluir sílabas e fonemas de palavras; identificar semelhanças entre sílabas iniciais, sílabas finais, fonemas iniciais, fonemas finais em diferentes palavras, entre tantas outras (MOOJEN et alii, 2003).

Segundo Moojen et alii (2003), há dois níveis de consciência fonológica: o implícito e o explícito. O implícito, menos refinado, é aquele em que se observa um simples jogo espontâneo com sons (em geral, a criança percebe unidades fonológicas mais globais, como a sílaba). $\mathrm{O}$ explícito é aquele em que a criança já faz uma análise mais consciente de unidades fonológicas constituintes das palavras, podendo, inclusive, transferir essa análise para a lectoescrita.

Baseados na concepção da existência desses dois níveis, Gough, Larson e Yopp (1996), sugerem que a consciência fonológica é mais adequadamente descrita em termos de uma estrutura hierárquica, que se desenvolve em um continuum, por meio de estágios, os quais começam com a 
consciência de unidades fonológicas mais globais até a consciência plena dos segmentos fonêmicos da fala.

A título de exemplo, pode-se dizer que, quando as crianças, de um modo geral, antes mesmo de serem alfabetizadas, brincam de rimar, o nível implícito se faz presente, ao passo que, quando mais velhas, já são capazes de segmentar palavras em silabas, em fonemas, o nível explícito fica mais evidente.

Sendo assim, a habilidade para rimar e para segmentar palavras em fonemas corresponderiam a diferentes pontos ao longo de um continuum, ao longo de uma escala baseada em diferentes graus de dificuldade.

Antes de finalizar essa seção, procede dizer que o termo consciência fonológica, a despeito de sua natureza linguística, foi utilizado, inicialmente, por psicólogos (STANOVICH,1994; SNOWLING, 2004; CAPOVILLA, 2000; entre outros), e não por linguistas, mostrando o quanto a linguística, ao menos durante algum tempo, ficou, de certo modo, à margem das discussões acerca do tema.

O estudo sobre a consciência fonológica é relevante tendo em vista a sua relação com a aprendizagem da leitura e da escrita, especialmente em sistemas alfabéticos, como é o caso da língua portuguesa.

\subsection{CONSCIÊNCIA FONOLÓGICA E APRENDIZAGEM DA LEITURA E DA ESCRITA}

A literatura aponta uma correlação entre o desenvolvimento da consciência fonológica e a aprendizagem da leitura e da escrita, no sentido de que o desempenho em tarefas de consciência fonológica pode, de certo modo, predizer como o indivíduo desenvolverá as habilidades de lectoescrita. Nesse sentido, há três abordagens teóricas sobre a relação entre consciência fonológica e a aprendizagem da leitura e da escrita: de causa, efeito e reciprocidade.

A primeira postula que a consciência fonológica favorece a aprendizagem da leitura e da escrita (BRYANT e BRADLEY, 1987; CARDOSO-MARTINS, 1995; CAPOVILLA e CAPOVILLA, 2000); a segunda (relação de efeito) entende que a aprendizagem da leitura e da escrita oportuniza o desenvolvimento da consciência fonológica (GOSWAMI e BRYANT, 1990 apud MOOJEN et alii, 2003; READ et alii, 1986; MORAIS, CARY, ALEGRIA e BERTELSON, 1986; PESTUN, 2005); e a terceira (relação de reciprocidade) sugere que tanto a consciência fonológica propicia a aprendizagem da lectoescrita, como essa aprendizagem aprimora o desenvolvimento de habilidades mais refinadas de consciência fonológica (PERFETTI, BECK, BALL e HUGHES, 1987; FREITAS, 2004).

O presente estudo abraça essa terceira concepção (reciprocidade), por entender que a aprendizagem da lectoescrita é processual, e que, portanto, requer o desenvolvimento prévio de algumas habilidades metafonológicas, assim como outras habilidades metafonológicas mais complexas derivam dessa aprendizagem. A consciência fonêmica, por exemplo, é apontada na literatura (MORAIS, 1997) como a última habilidade a emergir, tendo em vista que ela demanda do indivíduo o entendimento de que as palavras são constituídas de unidades menores (fonemas) que a sílaba.

A relação de reciprocidade entre consciência fonológica e aprendizagem da leitura e da escrita também esclarece a razão pela qual algumas habilidades metafonológicas são adquiridas antes, durante e depois da aprendizagem da lectoescrita: "Há possibilidade de que a criança antes de iniciar o processo de aquisição da escrita, já possua algumas habilidades metafonológicas e que, através do contato com a escrita, desenvolva outras e aprimore aquelas que já possui" (MOOJEN et alii, 2003, p. 12). 
Essa estreita relação entre aprendizagem da leitura e da escrita e consciência fonológica permite um melhor entendimento de que disléxicos, em geral, exibem dificuldades para desempenhar tarefas de consciência fonológica. A próxima seção abordará justamente o tema dislexia e os impactos desse transtorno linguístico na execução de tarefas envolvendo consciência fonológica.

\subsection{DISLEXIA E CONSCIÊNCIA FONOLÓGICA}

A dislexia é um transtorno específico de aprendizagem da leitura, de origem neurológica e de base congênita, que se caracteriza pela dificuldade do indivíduo para realizar decodificação e soletração de palavras, assim como pela dificuldade para executar uma leitura fluente. Consequentemente, a interpretação de textos lidos fica prejudicada, o que pode comprometer a escolaridade.

Em geral, o indivíduo disléxico apresenta um fracasso inesperado na leitura (e na escrita), a despeito de possuir inteligência normal, boa saúde, órgãos sensoriais intactos e instrução formal adequada. Normalmente, o transtorno manifesta-se no período escolar, sobretudo na alfabetização, embora alguns indícios já estejam presentes na pré-escola.

Historicamente, um dos primeiros estudos sobre a dislexia remonta ao final do século XIX, na Grã-Bretanha, onde houve uma proliferação de artigos científicos de médicos, oftalmologistas na sua maioria, sendo essa uma das razões da dislexia ter sido, inicialmente, associada a distúrbios do sistema visual.

Os trabalhos do médico Hinshelwood (1896) são um marco nos estudos iniciais sobre dislexia. Em artigo publicado no periódico The Lancet, em 1896, o autor descreve o caso de um paciente de 45 anos, alfaiate, repentinamente incapacitado de ler, a despeito da ausência de problemas ligados à sua acuidade visual e ao seu sistema nervoso.

W. Pringle Morgan (1896), também médico inglês, apresenta uma das primeiras descrições da dislexia no British Medical Journal, onde relata o caso de um rapaz, Percy, de 14 anos de idade, incapacitado de ler, apesar de possuir inteligência normal.

Por volta de 1917, os estudos sobre dislexia também florescem nos Estados Unidos, sobretudo com os trabalhos do neuroanatomista Samuel Orton (1925), que hipotetiza ser a dislexia fruto de um mau funcionamento do cérebro, ou seja, resultado de um conflito entre os hemisférios direito e esquerdo, que explicaria, por exemplo, a chamada escrita espelhada ou estrefossimbolia, bastante comum na dislexia. Samuel Orton é o primeiro a sugerir a possibilidade de tratamento para o transtorno.

Após os anos cinquenta, os estudos sobre dislexia, antes restritos, principalmente, a oftalmologistas e neurologistas, passam a ser de interesse também de profissionais de áreas como psicologia e educação, desencadeando, assim, novas explicações para os problemas de leitura.

Após os anos setenta, com o florescimento da psicologia cognitiva, "estudo de como as pessoas percebem, aprendem, lembram-se de algo e pensam sobre as informações" (STERNBERG, 2008, p. 19), médicos, psicólogos e educadores discutem temas como dislexia e cognição, dislexia e processamento visual, dislexia e processamento auditivo, dislexia e processamento linguístico, sobretudo processamento fonológico, métodos de remediação, entre outros.

A ideia de um processamento fonológico deficitário na dislexia foi amplamente aceita por vários estudiosos, entre os quais, Peter Bryant, Lynnette Bradley (1987), Frank Vellutino (1987), Keith Stanovich (1994), Bruce Pennington (1999), Margareth Snowling e Joy Stackhouse (2004) e Sally Shaywitz (2006). 
De um modo geral, esses estudos chamam a atenção para o fato de que o déficit no componente fonológico da linguagem conduz a um mapeamento mental deficitário de aspectos fonológicos, o qual, por sua vez, conduz o indivíduo a ter uma série de dificuldades linguísticas, como, por exemplo: a) estabelecer relações entre grafemas e fonemas; b) identificar e produzir rimas; c) segmentar palavras em unidades mais globais (sílabas ) e em unidades menores (fonemas); d) juntar, excluir e transpor sílabas e fonemas em palavras. Em outras palavras, a literatura aponta que a dislexia exerce um impacto na execução de tarefas de consciência fonológica.

Bryant e Bradley (1987) evidenciaram que crianças disléxicas tinham mais dificuldade para reconhecer e produzir rimas do que crianças normais. O estudo envolveu 60 sujeitos disléxicos de 10 anos e 60 não disléxicos de 7 anos, emparelhados pela idade de leitura, e não pela idade cronológica. Uma das tarefas era decidir, de um grupo de quatro palavras, qual delas não rimava; a outra era a produção de um maior número possível de palavras que rimassem com uma palavraestímulo apresentada pelo examinador. Bryant e Bradley contataram que, em ambas as tarefas, as crianças disléxicas haviam cometido mais erros.

\section{METODOLOGIA}

Esse estudo, de corte transversal, envolveu uma amostra constituída de 23 sujeitos disléxicos, 09 meninas e 14 meninos, todos alunos da rede privada de ensino, nas faixas etárias compreendidas entre 8;0 e 14;11, conforme segue: de 8;0 a 8;11 (7 sujeitos); de 9;0 a 9;11 (5 sujeitos); de 10;0 a 10;11 (6 sujeitos); de 11;0 a 11;11 (1 sujeito); de 12;0 a 12;11 (2 sujeitos); de 13;0 a 13;11 (1 sujeito); e de 14;0 a 14;11 (1 sujeito).

Os dados caracterizam-se como secundários, tendo em vista que haviam sido coletados, durante a elaboração da tese de doutorado sobre dislexia e processos fonológicos (PEPE, 2010). $\mathrm{Na}$ ocasião, os pacientes disléxicos já haviam realizado avaliação neurológica, fonoaudiológica e psicopedagógica, e os critérios de inclusão desses indivíduos na pesquisa foram: a) todos serem falantes do português com diagnóstico de dislexia do desenvolvimento; b) idade mínima de 8 anos; c) grau de escolaridade parental superior ou nível médio completo; d) ausência de privação sócio-cultural com interferência na aprendizagem; e) ausência de aparentes déficits sensoriais ou fono-articulatórios; f) ausência de retardo mental; g) ausência de lesão cerebral; e h) potencial cognitivo normal.

O instrumento utilizado para a coleta de dados foi o teste de consciência fonológica, CONFIAS- Consciência Fonológica: Instrumento de Avaliação Sequencial (MOOJEN et alii, 2003), cujo objetivo é avaliar a consciência fonológica nos níveis da sílaba (S) e do fonema (F), mediante a aplicação oral de 09 tarefas no primeiro nível e de 07 tarefas no segundo. Integram o teste: 01 manual de instruções, 01 folha de respostas (uso individual) e 07 pranchas com desenhos.

A fim de facilitar a elaboração de tabelas, quadros e gráficos, optou-se, no presente estudo, pela utilização de formas abreviadas, as quais podem ser visualizadas entre parênteses.

Tarefas no nível da sílaba (S)

S1- Síntese (Sint)

S2-Segmentação (Seg)

S3-Identificação de sílaba inicial (Id sil inic)

S4-Identificação de rima (Id rima)

S5-Produção de palavra com sílaba dada (Prod pal sil dada)

S6-Identificação de sílaba medial (Id sil med)

S7- Produção de rima (Prod rima)

S8-Exclusão (Excl) 
S9-Transposição (Transp)

Tarefas no nível do fonema (F):

F1-Produção de palavra que inicia com o som dado (Prod pal inic som dado)

F2-Identificação de fonema inicial (Id fon inic)

F3-Identificação de fonema final (Id fon fin)

F4-Exclusão (Excl)

F5-Síntese (Sint)

F6-Segmentação (Seg)

F7-Transposição (Transp)

A numeração baseia-se em uma escala crescente de dificuldade da tarefa: quanto menor o número, menor esse grau. Assim, de acordo com os critérios adotados pelo CONFIAS, a tarefa S1 é considerada mais simples e, portanto, mais fácil de ser executada do que a tarefa S2, que, por sua vez, é tida como mais fácil do que a S3, e assim sucessivamente.

A pontuação obtida por cada sujeito é registrada em uma folha de resposta, conforme havia sido mencionado anteriormente. Para o nível da sílaba (S), há 40 possibilidades de acerto; para o nível do fonema (F), 30 possibilidades, ou seja, 70 pontos representam a pontuação máxima no teste, o que corresponde a 100\% de acertos. Registra-se 1 (um) ponto para cada acerto e 0 (zero) para cada erro, valendo lembrar que as palavras podem ser repetidas pelo examinador apenas uma vez, pois, caso contrário, a resposta deve ser desconsiderada e, portanto, receber pontuação 0 (zero).

O ponto de corte adotado nesse estudo, Consciência fonológica de vinte e três disléxicos falantes do português, foi de 75\%, ou seja, uma habilidade de consciência fonológica foi considerada adquirida quando o desempenho do sujeito testado atingia esse percentual (a esse respeito, vide INGRAM, 1976; GRUNWELL, 1982; TEIXEIRA, 1991; YAVAS, HERNANDORENA e LAMPRECHT, 1991 e outros).

A aplicação do instrumento ocorreu em sessões individuais, com duração de uma hora (1h), aproximadamente, e os dados coletados foram, posteriormente, tabulados. Todas as instruções foram dadas oralmente, conforme detalhado no manual de instruções do CONFIAS.

As tarefas S3- Identificação de sílaba inicial, S4-Identificação de rima, S6-Identificação de sílaba medial, S7- Produção de rima, F2-Identificação de fonema inicial e F3-Identificação de fonema final contaram com o apoio de desenhos, cujas pranchas já fazem parte do próprio CONFIAS.

Dito isso, apresenta-se, a seguir, a descrição das tarefas do CONFIAS.

\section{Tarefas no nível da sílaba (S)}

S1- Síntese (Sint). Nessa tarefa, o sujeito deve unir as sílabas das palavras alvo. Estímulos: bi-co, sor-ve-te, má-gi-co; e-le-fan-te. Respostas: bico, sorvete, mágico, elefante S2- Segmentação (Seg). Aqui, o sujeito deve separar as sílabas das palavras-alvo. Palavras-alvo: gato, abacaxi, cachorro, escova. Respostas: ga-to; a-ba-ca-xi; ca-cho-rro; e-le-fan-te. S3- Identificação de sílaba inicial (Id sil inic). Dado um desenho e três opções de palavras, o sujeito identifica qual das três inicia com o mesmo som da palavra representada no desenho.

Desenho: faca. Opções: fada-vaso-lata Resposta: fada

Desenho: pipoca Opções: sapato-piscina-bigode Resposta: piscina

Desenho: cabide Opções: bandeira-palito-carroça Resposta: carroça

Desenho: cenoura Opções: raposa-semana-chinelo Resposta: semana

S4-Identificação de rima (Id rima). Dado um desenho e três opções de palavras, o sujeito identifica qual das três rima com a palavra representada no desenho. 
Desenho: flor Opções: pão-dor-trem Resposta: flor

Desenho: martelo Opções: morango-tapete-castelo Resposta: castelo

Desenho: abelha Opções: relógio-orelha-vestido Resposta: orelha

Desenho: coração Opções: armazém-carnaval-inję̧ão Resposta: injeção

S5- Produção de palavra com sílaba dada (Prod pal sil dada). Dadas as sílabas $c a, b a$, $p i$ e so, esperase que o sujeito apresente, oralmente, exemplos (um de cada) de palavras iniciando com essas sílabas.

Respostas possíveis: casa, bata, pipoca, sopa

S6- Identificação de sílaba medial (Id sil med). Dado um desenho e três opções de palavras, o sujeito diz qual das três possui a sílaba medial igual à da palavra do desenho.

Desenho: tomate Opções: fumaça-lanterna-espeto Resposta: fumaça

Desenho: palhaço Opções: mochila-caneta-telhado Resposta: telhado

Desenho: cavalo Opções: solado-gravata-vizinho Resposta: gravata

Desenho: jacaré Opções: avental-macarrão-dominó Reposta: macarrão

S7- Produção de rima (Prod rima). Dado um desenho e três opções de palavras, o sujeito diz qual das três rima com a palavra representada pelo desenho.

Desenho: balão Reposta possível: sabão

Desenho: café Resposta possível: chulé

Desenho: rato Resposta possível: gato

Desenho: bola Resposta possível: cola

S8- Exclusão (Excl). A tarefa aqui é o sujeito dizer a palavra que fica após uma de suas sílabas ser excluída.

Estímulo: cipó Sílaba a ser excluída: ci Resposta: pó

Estímulo: piolho Sílaba a ser excluída: pi Resposta: olbo

Estímulo: escola Sílaba a ser excluída: es Resposta: cola

Estímulo: gaveta Sílaba a ser excluída: ve Resposta: gata

Estímulo: pele Sílaba a ser excluída: le Resposta: pé

Estímulo: gasto Sílaba a ser excluída: to Resposta: gás

Estímulo: caracol Sílaba a ser excluída: col Resposta: cara

S9- Transposição. Dada uma palavra sem sentido (estímulo), em virtude de suas sílabas estarem invertidas, o sujeito deve dizer, a última sílaba e, depois, dizer a primeira sílaba, de modo a produzir uma palavra real.

Estímulo: tapor Resposta: porta

Estímulo: lhomi Resposta: milho

Estímulo: cafó Resposta: foca

Estímulo: valú Resposta: luva

Tarefas no nível do fonema (F):

F1-Produção de palavra que inicia com o som dado (Prod pal inic som dado). Dado um fone como estímulo, o sujeito deve dizer uma palavra iniciando com o fone dado.

Estímulo: $[\square \square] \square \square$ Resposta possível: jato

Estímulo: [ $\square \square] \square \square$ Resposta possível: veaca

Estímulo: $\square[\square \square]$ Resposta possível: $\underline{\text { chuva }}$

Estímulo: $\square \square \square]$ Resposta possível: s sapo

F2-Identificação de fonema inicial (Id fon inic). Dado um desenho e três opções de palavras, o sujeito deve identificar qual das três inicia com o som da palavra representada no desenho.

Desenho: urso Opções: ovo-bolo-unha Resposta: unha 
Desenho: folha Opções: vela-figo-cola Resposta: figo

Desenho: macaco Opções: menino-presente-salada Resposta: menino

Desenho: dedo Opções: doce-sapo-linha Resposta: doce

F3-Identificação de fonema final (Id fon fin). Dado um desenho e três opções de palavras, o sujeito deve identificar qual delas termina com o som final da palavra representada no desenho.

Desenho: lápis Opções: pedra-garfo-férias Resposta: féria

Desenho: tambor Opções: nariz-colher-manhã Resposta: colher

Desenho: piano Opções: criança-cidade-banheiro Resposta: banheiro

Desenho: escada Opções: cabeça-parede-morcego Resposta: cabeça.

F4-Exclusão (Excl). Dada uma palavra como estímulo e um fone a ser excluído, o sujeito deve dizer que palavra resulta dessa exclusão.

Estímulo: mar Fone a ser excluído: [r] (sic) ${ }^{1}$ Resposta: ma

Estímulo: jaula Fone a ser excluído: [ ${ }^{\star}$ ] Resposta: aula

Estímulo: vida Fone a ser excluído: [v ] Resposta: $i d a$

Estímulo: pasta Fone a ser excluído: [ s ] Resposta: pata

Estímulo: peça ['p $\square \mathrm{s} a]^{2}$ Fone a ser excluído: [a] Reposta: pés [p $\square \mathrm{s}$ ]

Estímulo: viúva Fone a ser excluído: [u] Resposta: viva

F5-Síntese (Sint). Dados os fones de uma palavra separadamente, o sujeito deve uni-los e dizer que palavra resulta dessa junção.

Estímulo: g-i-z [犬] [i] [s] Resposta: giz [C*is]

Estímulo: u-v-a [u] [v] [a] Resposta: wva ['uva]

Estímulo: a-s-a [a] [z] [a] Resposta:asa ['aza]

Estímulo: m-a-l-a [m] [a] [1] [a] Resposta: mala ['mala]

F6-Segmentação. Dada uma palavra como estímulo, o sujeito deve dividi-la em seus respectivos fones.

Estímulo: chá $[\square$ a] Resposta: ch-á $\square][a]$

Estímulo: osso ['osu] Resposta: o-ss-o [o] [s] [u]

Estímulo: lixo ['i $\square \mathrm{u}]$ Resposta: $l-i-x-0 \quad[1][i][\square] \square[\mathrm{u}]$

Estímulo: mola ['mola] Resposta: $m-o-l-a[\mathrm{~m}]$ [0] [1] $\square$ [a]

F7-Transposição. O sujeito deve dizer a palavra dada como estímulo de trás para a frente.

Estímulo: alé [a'1 $\square$ ] Resposta: ela [' $\square$ la]

Estímulo: óva ['ova] Resposta: avó [a'vo] Estímulo)

Estímulo ôla [' $\square$ la] Resposta: alô [a'lo]

Estímulo: ias [ias] Resposta: sai [say] (sic)

\section{ANÁLISE DOS DADOS E DISCUSSÃO DOS RESULTADOS}

O exame do desempenho dos sujeitos nas tarefas de consciência fonológica nos níveis da sílaba e do fonema (Tabela 1) ${ }^{3}$ evidencia o desenvolvimento da consciência fonológica ainda em

\footnotetext{
${ }^{1}$ Vale lembrar que essa consoante final não se manifesta foneticamente como vibrante múltipla na norma soteropolitana.

${ }^{2}$ Conquanto a vogal /a/ em posição final de palavra (não acentuada) seja representada foneticamente pela variante posicional $[\mathfrak{e}]$, optou-se aqui pela manutenção do [a] final, de modo a manter uma harmonia visual entre a forma escrita e a transcrição fonética.

${ }^{3}$ Utilizou-se a média ponderada em todas as tabelas, tendo em vista os diferentes pesos das tarefas nos níveis de sílaba e do fonema.
} 
curso (63,0\% média geral); e um maior desenvolvimento de habilidades no nível da sílaba $(71,2 \%)$ do que no nível do fonema (52,3\%), em virtude da a unidade fonológica sílaba ser mais perceptível do que a unidade fonológica fonema.

\begin{tabular}{|c|c|c|c|}
\hline & (S) & $(\mathrm{F})$ & Média \\
\hline Sujeito 1 & $97,5 \%$ & $96,7 \%$ & $97,1 \%$ \\
\hline Sujeito 2 & $77,5 \%$ & $66,7 \%$ & $72,9 \%$ \\
\hline Sujeito 3 & $67,5 \%$ & $36,7 \%$ & $54,3 \%$ \\
\hline Sujeito 4 & $72,0 \%$ & $60,0 \%$ & $66,7 \%$ \\
\hline Sujeito 5 & $55,0 \%$ & $46,7 \%$ & $51,4 \%$ \\
\hline Sujeito 6 & $95,0 \%$ & $73,3 \%$ & $85,7 \%$ \\
\hline Sujeito 7 & $80,0 \%$ & $53,3 \%$ & $68,6 \%$ \\
\hline Sujeito 8 & $90,0 \%$ & $56,7 \%$ & $75,7 \%$ \\
\hline Sujeito 9 & $72,5 \%$ & $53,3 \%$ & $64,3 \%$ \\
\hline Sujeito 10 & $52,5 \%$ & $40,0 \%$ & $47,1 \%$ \\
\hline Sujeito 11 & $85,0 \%$ & $70,0 \%$ & $78,6 \%$ \\
\hline Sujeito 12 & $66,7 \%$ & $46,7 \%$ & $57,6 \%$ \\
\hline Sujeito 13 & $62,5 \%$ & $44,0 \%$ & $52,3 \%$ \\
\hline Sujeito 14 & $74,4 \%$ & $40,0 \%$ & $59,4 \%$ \\
\hline Sujeito 15 & $70,0 \%$ & $46,7 \%$ & $60,0 \%$ \\
\hline Sujeito 16 & $57,5 \%$ & $36,7 \%$ & $48,6 \%$ \\
\hline Sujeito 17 & $55,0 \%$ & $27,6 \%$ & $43,5 \%$ \\
\hline Sujeito 18 & $75,0 \%$ & $66,7 \%$ & $71,4 \%$ \\
\hline Sujeito 19 & $67,5 \%$ & $51,7 \%$ & $60,9 \%$ \\
\hline Sujeito 20 & $57,5 \%$ & $23,3 \%$ & $42,9 \%$ \\
\hline Sujeito 21 & $55,0 \%$ & $34,5 \%$ & $46,4 \%$ \\
\hline Sujeito 22 & $77,5 \%$ & $63,3 \%$ & $71,4 \%$ \\
\hline Sujeito 23 & $74,4 \%$ & $69,0 \%$ & $72,1 \%$ \\
\hline Media Geral & $71,2 \%$ & $52,3 \%$ & $63,0 \%$ \\
\hline
\end{tabular}

Tabela 1 - Desempenho dos sujeitos em tarefas nos níveis da sílaba (S) e do fonema (F).

A Tabela 1 também mostra que dos 23 sujeitos investigados, 15 estão em fase de consolidação da consciência fonológica, tendo em vista que suas médias foram, respectivamente: Sujeito $3(54,3 \%)$, Sujeito $4(66,7 \%)$, Sujeito $5(51,4 \%)$, Sujeito $7(68,6 \%)$, Sujeito $9(64,3 \%)$, Sujeito $10(47,1 \%)$, Sujeito 12 (57,6\%), Sujeito13 (52,3\%), Sujeito 14 (59,4\%), Sujeito 15 (60,0\%), Sujeito $16(48,6 \%)$, Sujeito 17 (43,5\%), Sujeito 19 (60,9\%), Sujeito $20(42,9 \%)$ e Sujeito 21 (46,4\%). 
Esses números indicam que mais da metade dos disléxicos estudados apresentaram dificuldades para realizar tarefas de consciência fonológica, corroborando a ideia de que os disléxicos investigados exibiram problemas envolvendo processamento fonológico e, por conseguinte, dificuldades para executar tarefas metafonológicas.

\subsection{AS TAREFAS NO NÍVEL DA SÍLABA}

As habilidades metafonológicas no nível da sílaba estão sendo consolidadas, tendo em vista que a média geral de acerto foi de $71,2 \%$ (Tabela 2). A tarefa de mais fácil execução foi a Segmentação (S2) com 97,8\% de acerto, contrariando o previsto no CONFIAS, segundo o qual a tarefa de Síntese (S1) é considerada a menos laboriosa. No estudo aqui conduzido, a Síntese (S1) apresentou-se com um percentual de acerto de $94,5 \%$, ficando um pouco abaixo da Segmentação (S2). A ela seguiram-se as tarefas de Produção de palavra com sílaba dada (S5), com 90,5\%, Identificação de sílaba inicial (S3), com 82,6\% e Identificação de rima (S4), com 78,8\%, todas consolidadas.

\begin{tabular}{|c|c|c|c|c|c|c|c|c|c|c|}
\hline & $\mathrm{S} 1$ & $\mathbf{S} 2$ & S3 & S4 & S5 & S6 & S7 & S8 & S9 & Média \\
\hline & Sint & Seg & $\begin{array}{l}\text { Id sil } \\
\text { inic }\end{array}$ & $\begin{array}{l}\text { Id } \\
\text { rima }\end{array}$ & $\begin{array}{l}\text { Prod pal sil } \\
\text { dada }\end{array}$ & $\begin{array}{l}\text { Id sil } \\
\text { med }\end{array}$ & $\begin{array}{l}\text { Prod } \\
\text { rima }\end{array}$ & Excl & Transp & \\
\hline Sujeito 1 & $100,0 \%$ & $100,0 \%$ & $75,0 \%$ & $100,0 \%$ & $100,0 \%$ & $100,0 \%$ & $100,0 \%$ & $100,0 \%$ & $100,0 \%$ & $97,5 \%$ \\
\hline Sujeito 2 & $100,0 \%$ & $100,0 \%$ & $100 \%$ & $75 \%$ & $100,0 \%$ & $50,0 \%$ & $100,0 \%$ & $100,0 \%$ & $100,0 \%$ & $77,5 \%$ \\
\hline Sujeito 3 & $100,0 \%$ & $100,0 \%$ & $100,0 \%$ & $100,0 \%$ & $50,0 \%$ & $50,0 \%$ & $50,0 \%$ & $50,0 \%$ & $75,0 \%$ & $67,5 \%$ \\
\hline Sujeito 4 & $100,0 \%$ & $100,0 \%$ & $75,0 \%$ & $75,0 \%$ & Não aplicada ${ }^{4}$ & $50,0 \%$ & $25,00 \%$ & $62,5 \%$ & $100,0 \%$ & $72,0 \%$ \\
\hline Sujeito 5 & $100,0 \%$ & $75,0 \%$ & $100,0 \%$ & $50,0 \%$ & $50,0 \%$ & $25,0 \%$ & $25,0 \%$ & $50,0 \%$ & $25,0 \%$ & $55,0 \%$ \\
\hline Sujeito 6 & $100,0 \%$ & $100,0 \%$ & $100,0 \%$ & $100,0 \%$ & $100,0 \%$ & $50,0 \%$ & $100,0 \%$ & $100,0 \%$ & $100,0 \%$ & $95,0 \%$ \\
\hline Sujeito 7 & $100,0 \%$ & $100,0 \%$ & $100,0 \%$ & $50,0 \%$ & $100,0 \%$ & $100,0 \%$ & $0,0 \%$ & $75,0 \%$ & $100,0 \%$ & $80,0 \%$ \\
\hline Sujeito 8 & $100,0 \%$ & $100,0 \%$ & $100,0 \%$ & $100,0 \%$ & $100,0 \%$ & $100,0 \%$ & $75,0 \%$ & $100,0 \%$ & $25,0 \%$ & $90,0 \%$ \\
\hline Sujeito 9 & $100,0 \%$ & $100,0 \%$ & $50,0 \%$ & $100,0 \%$ & $75,0 \%$ & $25,0 \%$ & $0,0 \%$ & $87,5 \%$ & $100,0 \%$ & $72,5 \%$ \\
\hline Sujeito 10 & $50,0 \%$ & $100,0 \%$ & $75,0 \%$ & $0,0 \%$ & $100,0 \%$ & $50,0 \%$ & $50,0 \%$ & $12,5 \%$ & $75,0 \%$ & $52,5 \%$ \\
\hline Sujeito 11 & $100,0 \%$ & $100,0 \%$ & $100,0 \%$ & $100,0 \%$ & $100,0 \%$ & $25,0 \%$ & $50,0 \%$ & $87,5 \%$ & $100,0 \%$ & $85,0 \%$ \\
\hline Sujeito 12 & $100,0 \%$ & $100,0 \%$ & $50,0 \%$ & $75,0 \%$ & Não aplicada & $0,0 \%$ & $25,0 \%$ & $75,0 \%$ & $100,0 \%$ & $66,7 \%$ \\
\hline Sujeito 13 & $100,0 \%$ & $75,0 \%$ & $100,0 \%$ & $50,0 \%$ & $100,0 \%$ & $75,0 \%$ & $25,0 \%$ & $50,0 \%$ & $0,0 \%$ & $62,5 \%$ \\
\hline
\end{tabular}

\footnotetext{
4 O termo "Não aplicada" indica que, por alguma razão, o examinador não aplicou aquela tarefa para aquele sujeito.
} 


\begin{tabular}{|c|c|c|c|c|c|c|c|c|c|c|}
\hline Sujeito 14 & $100,0 \%$ & $100,0 \%$ & $100,0 \%$ & $75,0 \%$ & $100,0 \%$ & $0,0 \%$ & $50,0 \%$ & $71,4 \%$ & $75,0 \%$ & $74,4 \%$ \\
\hline Sujeito 15 & $100,0 \%$ & $100,0 \%$ & $75,0 \%$ & $100,0 \%$ & $100,0 \%$ & $75,0 \%$ & $25,0 \%$ & $62,5 \%$ & $0,0 \%$ & $70,0 \%$ \\
\hline Sujeito 16 & $50,0 \%$ & $100,0 \%$ & $100,0 \%$ & $75,0 \%$ & $75,0 \%$ & $0,0 \%$ & $0,0 \%$ & $62,5 \%$ & $50,0 \%$ & $57,5 \%$ \\
\hline Sujeito 17 & $100,0 \%$ & $100,0 \%$ & $75,0 \%$ & $75,0 \%$ & $100,0 \%$ & $0,0 \%$ & $50,0 \%$ & $25,0 \%$ & $0,0 \%$ & $55,0 \%$ \\
\hline Sujeito 18 & $100,0 \%$ & $100,0 \%$ & $100,0 \%$ & $75,0 \%$ & $100,0 \%$ & $25,0 \%$ & $25,0 \%$ & $62,5 \%$ & $100,0 \%$ & $75,0 \%$ \\
\hline Sujeito 19 & $100,0 \%$ & $100,0 \%$ & $50,0 \%$ & $50,0 \%$ & $100,0 \%$ & $0,0 \%$ & $25,0 \%$ & $75,0 \%$ & $100,0 \%$ & $67,5 \%$ \\
\hline Sujeito 20 & $100,0 \%$ & $100,0 \%$ & $100,0 \%$ & $50,0 \%$ & $75,0 \%$ & $50,0 \%$ & $0,0 \%$ & $37,5 \%$ & $25,0 \%$ & $57,5 \%$ \\
\hline Sujeito 21 & $75,0 \%$ & $100,0 \%$ & $100,0 \%$ & $50,0 \%$ & $75,0 \%$ & $0,0 \%$ & $50,0 \%$ & $50,0 \%$ & $0,0 \%$ & $55,0 \%$ \\
\hline Sujeito 22 & $100,0 \%$ & $100,0 \%$ & $75,0 \%$ & $75,0 \%$ & $100,0 \%$ & $50,0 \%$ & $50,0 \%$ & $75,0 \%$ & $75,0 \%$ & $77,5 \%$ \\
\hline Sujeito 23 & $100,0 \%$ & $100,0 \%$ & $75,0 \%$ & $75,0 \%$ & $100,0 \%$ & $50,0 \%$ & $25,0 \%$ & $87,5 \%$ & $50,0 \%$ & $74,4 \%$ \\
\hline Média & $94,5 \%$ & $97,8 \%$ & $82,6 \%$ & $78,8 \%$ & $90,5 \%$ & $41,3 \%$ & $40,2 \%$ & $67,8 \%$ & $64,1 \%$ & $71,2 \%$ \\
\hline
\end{tabular}

Exclusão, S8(67,8\%), e a Transposição, S9 (64,1\%), habilidades ainda não consolidadas, ocuparam uma posição intermediária, considerando que seus percentuais já se aproximam dos $75,0 \%$, percentual adotado como ponto de corte neste estudo.

Produção de rima, S7, $(40,2 \%)$ representou a tarefa mais difícil de ser realizada, seguindose a ela a Identificação de sílaba medial (S6), com 41,3\%.

Adotando o critério grau crescente de dificuldade, as tarefas no nível da sílaba ocuparam a seguinte ordem na escala: Segmentação (S2) $\rightarrow$ Síntese $(\mathrm{S} 1) \rightarrow$ Produção de palavra com sílaba dada (S5) $\rightarrow$ Identificação de sílaba inicial (S3) $\rightarrow$ Identificação de rima $(\mathrm{S} 4) \rightarrow$ Exclusão(S8) $\rightarrow$ Transposição (S9) $\rightarrow$ Identificação de sílaba medial (S6) $\rightarrow$ Produção de rima (S7).

Vale lembrar que um estudo conduzido por Bryant e Bradley (1987) havia identificado a Produção de rima como uma das tarefas mais laboriosas para os sujeitos disléxicos por eles investigados. executada.

Cerqueira (2016) também identificou ser a Produção de rima a mais difícil de ser

Santana (2016), em seu estudo sobre consciência fonológica em alunos do $1^{\circ}$ e $2^{\circ}$ anos do ensino fundamental de uma escola montessoriana, após aplicação do CONFIAS, também aponta a Produção de rima como a tarefa mais laboriosa de ser executada. A seguir, comentários sobre cada uma das tarefas no nível da sílaba:

SÍNTESE (S1)

A habilidade para unir sílabas mostrou-se consolidada, pois apenas dois sujeitos exibiram dificuldades com essa tarefa: o Sujeito 10 e o Sujeito 16, ambos com 50\% de acerto.

SEGMENTAÇÃO (S2) 
A habilidade para segmentar sílabas pode ser considerada adquirida, tendo em vista que os percentuais de acerto foram de 75,0\% (Sujeitos 5 e 13) e 100,0\% (todos os demais sujeitos). Os sujeitos disléxicos que compuseram a amostra não revelaram maiores problemas para lidar com a segmentação silábica.

IDENTIFICAÇÃO DE SÍLABA INICIAL (S3)

A Identificação de sílaba inicial (S3), de um modo geral, foi executada satisfatoriamente, tendo em vista que apenas três sujeitos obtiveram 50,0\%, os Sujeitos 9, 12 e 19. Os demais ficaram com percentuais em torno de 75,0\% a 100,0\%.

IDENTIFICAÇÃO DE RIMA (S4)

A Identificação de rima $(78,8 \%)$, conquanto tenha sido uma tarefa executada satisatoriamente pela maioria dos indivíduos, mostrou-se bastante laboriosa para o Sujeito 10 $(0,0 \%)$; e para os Sujeitos 5, 7, 13, 19, 20 e $21(50,0 \%)$, revelou-se uma habilidade que está sendo adquirida. Particularmente no que diz respeito ao Sujeito 10, observou-se que o seu percentual $(0,0 \%)$ foi consequência de opções incorretas que o mesmo fez para as alternativas a ele apresentadas.

PRODUÇÃO DE PALAVRA COM SÍLABA DADA (S5)

$\mathrm{Na}$ Produção de palavra com sílaba dada (S5), apenas os Sujeitos 3 e $5(50,0 \%)$ ainda não desenvolveram totalmente essa habilidade metafonológica, tendo em vista que os demais obtiveram percentuais em torno de $75,0 \%$ a $100,0 \%$ de acerto.

IDENTIFICAÇÃO DE SÍLABA MEDIAL (S6)

A Identificação de sílaba medial $(41,3 \%)$ revelou-se uma tarefa bastante difícil para a maioria dos escolares testados, pois, excetuando-se os sujeitos 1, 7, 8 (100,0\%); e 13 e 15 (75,0\%), os demais ou ainda não desenvolveram essa habilidade, como é o caso dos sujeitos $12,14,16,17$, 19 e $21(0,0 \%)$, ou estão em fase de desenvolvimento da mesma, como é o caso dos sujeitos 5,9 , 11 e $18(25,0 \%)$, e $2,3,4,6,10,20,22$ e $23(50,0 \%)$.

Vale salientar que a dificuldade para identificar sílabas mediais já havia sido apontada em outros estudos, a exemplo da investigação de Carvalho (2003), segundo o qual essa dificuldade pode estar relacionada a dois fatores: à extensão lexical (trissílabos) e à posição da sílaba na estrutura da palavra. Ambos, então, adicionariam dificuldades de processamento, uma vez que demandam maior capacidade de memória fonológica.

Costa (2012), ao investigar a consciência fonológica em alunos da Educação de Jovens e Adultos (EJA), também constata ser a Identificação de sílaba medial uma das tarefas mais laboriosas.

PRODUÇÃO DE RIMA (S7)

$\mathrm{Na}$ Produção de rima (40,2\%), apenas quatro pesquisados, Sujeitos 1, 2, $6(100,0 \%)$ e 8 $(75,0 \%)$, obtiveram êxito, ou seja, grande parte dos indivíduos testados demonstrou ser essa atividade a mais difícil de ser executada, como revelam os percentuais a seguir: Sujeitos 7, 9, 16 e 20 (0,0\%); Sujeitos 4, 5, 12, 13, 15, 18, 19 e 23 (25,0\%); Sujeitos 3, 10, 11, 14, 17, 21 e 22 (50,0\%). EXCLUSÃO (S8)

A Exclusão $(67,8 \%)$ foi realizada com dificuldade por mais da metade dos sujeitos testados, uma vez que os percentuais de acerto foram os seguintes: Sujeito 10 (12,5\%), Sujeito 17 $(25,0 \%)$, Sujeito 20 (37,5\%), Sujeitos 3, 5, 13 e 21 (50,0\%), Sujeitos 4, 15, 16 e 18 (62,5\%); e Sujeito $14(71,4 \%)$.

TRANSPOSIÇÃO (S9)

$\mathrm{Na}$ tarefa de Transposição (64,1\%), quatro sujeitos $(13,15,17$ e 21$)$ ainda não desenvolveram essa habilidade $(0,0 \%)$; três $(5,8$ e 20$)$ acertaram menos da metade $(25,0 \%)$ das 
tarefas; e dois (16 e 23) realizaram metade $(50,0 \%)$ das atividades corretamente. A Transposição, portanto, mostrou-se como uma habilidade ainda não consolidada.

\subsection{AS TAREFAS NO NÍVEL DO FONEMA}

As habilidades metafonológicas no nível fonema (Tabela 3), comparadas àquelas no nível da sílaba, estão mais longe de ser consolidadas, tendo em vista que a média geral de acertos foi de 52,3\%. A tarefa mais fácil foi a de Produção de palavra que inicia com som dado, F1 (84,8\%), ratificando o previsto no CONFIAS.

\begin{tabular}{|c|c|c|c|c|c|c|c|c|}
\hline Sujeitos & $\begin{array}{c}\text { F1 } \\
\text { Prod pal inic } \\
\text { som dado }\end{array}$ & $\begin{array}{l}\text { F2 } \\
\text { Id fon } \\
\text { inic }\end{array}$ & $\begin{array}{c}\text { F3 } \\
\text { Id fon fin }\end{array}$ & $\begin{array}{c}\text { F4 } \\
\text { Excl }\end{array}$ & $\begin{array}{l}\text { F5 } \\
\text { Sint }\end{array}$ & $\begin{array}{l}\text { F6 } \\
\text { Seg }\end{array}$ & $\begin{array}{c}\text { F7 } \\
\text { Transp }\end{array}$ & Média \\
\hline Sujeito 1 & $100,0 \%$ & $100,0 \%$ & $75,0 \%$ & $\begin{array}{c}100,0 \\
\%\end{array}$ & $100,0 \%$ & $100,0 \%$ & $100,0 \%$ & $96,7 \%$ \\
\hline Sujeito 2 & $100,0 \%$ & $100,0 \%$ & $25,0 \%$ & $83,3 \%$ & $75,0 \%$ & $25,0 \%$ & $50,0 \%$ & $66,7 \%$ \\
\hline Sujeito 3 & $75,0 \%$ & $75,0 \%$ & $50,0 \%$ & $16,7 \%$ & $50,0 \%$ & $0,0 \%$ & $0,0 \%$ & $36,7 \%$ \\
\hline Sujeito 4 & $100,0 \%$ & $100,0 \%$ & $50,0 \%$ & $16,7 \%$ & $100,0 \%$ & $75,0 \%$ & $0,0 \%$ & $60,0 \%$ \\
\hline Sujeito 5 & $100,0 \%$ & $75,0 \%$ & $75,0 \%$ & $16,7 \%$ & $75,0 \%$ & $0,0 \%$ & $0,0 \%$ & $46,7 \%$ \\
\hline Sujeito 6 & $100,0 \%$ & $100,0 \%$ & $75,0 \%$ & $66,7 \%$ & $75,0 \%$ & $50,0 \%$ & $25,0 \%$ & $73,3 \%$ \\
\hline Sujeito 7 & $75,0 \%$ & $75,0 \%$ & $75,0 \%$ & $66,7 \%$ & $75,0 \%$ & $0,0 \%$ & $0,0 \%$ & $53,3 \%$ \\
\hline Sujeito 8 & $75,0 \%$ & $100,0 \%$ & $0,0 \%$ & $33,3 \%$ & $75,0 \%$ & $100,0 \%$ & $0,0 \%$ & $56,7 \%$ \\
\hline Sujeito 9 & $100,0 \%$ & $50,0 \%$ & $50,0 \%$ & $33,3 \%$ & $50,0 \%$ & $50,0 \%$ & $25,0 \%$ & $53,3 \%$ \\
\hline Sujeito 10 & $100,0 \%$ & $50,0 \%$ & $50,0 \%$ & $16,7 \%$ & $75,0 \%$ & $0,0 \%$ & $0,0 \%$ & $40,0 \%$ \\
\hline Sujeito 11 & $100,0 \%$ & $75,0 \%$ & $75,0 \%$ & $66,7 \%$ & $100,0 \%$ & $25,0 \%$ & $25,0 \%$ & $70,0 \%$ \\
\hline Sujeito 12 & $75,0 \%$ & $75,0 \%$ & $25,0 \%$ & $66,7 \%$ & $0,0 \%$ & $0,0 \%$ & $75,0 \%$ & $46,7 \%$ \\
\hline Sujeito 13 & $50,0 \%$ & $100,0 \%$ & Não Aplicada & $40,0 \%$ & $0,0 \%$ & $25,0 \%$ & $0,0 \%$ & $44,0 \%$ \\
\hline Sujeito 14 & $100,0 \%$ & $75,0 \%$ & $25,0 \%$ & $33,3 \%$ & $50,0 \%$ & $0,0 \%$ & $0,0 \%$ & $43,3 \%$ \\
\hline Sujeito 15 & $100,0 \%$ & $50,0 \%$ & $100,0 \%$ & $0,0 \%$ & $50,0 \%$ & $50,0 \%$ & $0,0 \%$ & $50,0 \%$ \\
\hline Sujeito 16 & $75,0 \%$ & $25,0 \%$ & $50,0 \%$ & $66,7 \%$ & $25,0 \%$ & $0,0 \%$ & $0,0 \%$ & $36,7 \%$ \\
\hline Sujeito 17 & $75,0 \%$ & $0,0 \%$ & $50,0 \%$ & $0,0 \%$ & $75,0 \%$ & $0,0 \%$ & $0,0 \%$ & $24,1 \%$ \\
\hline Sujeito 18 & $75,0 \%$ & $75,0 \%$ & $50,0 \%$ & $66,7 \%$ & $75,0 \%$ & $100,0 \%$ & $0,0 \%$ & $66,7 \%$ \\
\hline Sujeito 19 & $75,0 \%$ & $50,0 \%$ & $0,0 \%$ & $50,0 \%$ & $50,0 \%$ & $50,0 \%$ & $100,0 \%$ & $51,7 \%$ \\
\hline Sujeito 20 & $25,0 \%$ & $75,0 \%$ & $0,0 \%$ & $0,0 \%$ & $50,0 \%$ & $0,0 \%$ & $25,0 \%$ & $23,3 \%$ \\
\hline Sujeito 21 & $75,0 \%$ & $100,0 \%$ & $25,0 \%$ & $0,0 \%$ & $25,0 \%$ & $0,0 \%$ & $33,3 \%$ & $34,5 \%$ \\
\hline Sujeito 22 & $100,0 \%$ & $100,0 \%$ & $50,0 \%$ & $33,3 \%$ & $75,0 \%$ & $100,0 \%$ & $0,0 \%$ & $63,3 \%$ \\
\hline Sujeito 23 & $100,0 \%$ & $100,0 \%$ & $50,0 \%$ & $80,0 \%$ & $75,0 \%$ & $50,0 \%$ & $25,0 \%$ & $69,0 \%$ \\
\hline Média & $84,8 \%$ & $75,0 \%$ & $46,6 \%$ & $41,4 \%$ & $60,9 \%$ & $34,8 \%$ & $21,0 \%$ & $52,3 \%$ \\
\hline
\end{tabular}

Tabela 3- Desempenho dos sujeitos em tarefas no nível do fonema (F). 
Mantendo, ainda, o previsto no CONFIAS, a Transposição (F7) (21,0\%) representou a tarefa mais difícil de ser executada.

A Identificação de fonema inicial (F2) $(75,0 \%)$ e a Segmentação (F6) $(34,8 \%)$ também confirmaram o previsto no teste, uma vez que a Identificação de fonema inicial (F2) foi a segunda tarefa mais fácil; e a Segmentação (F6) também manteve a sexta posição, ficando à frente da Transposição (F7).

Os dados coletados mostraram que, partindo das mais fáceis para as mais difíceis, as tarefas no nível do fonema apresentaram a seguinte configuração: Produção de palavra que inicia com som dado (F1) $\rightarrow$ Identificação de fonema inicial (F2) $\rightarrow$ Síntese (F5) $\rightarrow$ Identificação de fonema final (F3) $\rightarrow$ Exclusão (F4) $\rightarrow$ Segmentação (F6) $\rightarrow$ Transposição (F7). Conforme pode ser visto, as duas primeiras tarefas $\mathrm{F} 1 \mathrm{e} \mathrm{F} 2$, e as duas últimas $\mathrm{F} 6$ e F7, mantiveram suas posições, quando comparadas às posições do CONFIAS.

Feitas algumas considerações sobre o desempenho geral dos sujeitos, no nível do fonema, apresenta-se, a seguir, o detalhamento de cada uma das tarefas nesse nível.

PRODUÇÃO DE PALAVRA QUE INICIA COM SOM DADO (F1)

Como pode ser visualizado na Tabela 3, apenas dois sujeitos, o Sujeito $13(50,0 \%)$ e o 20 $(25,0 \%)$ ainda não desenvolveram plenamente essa habilidade, pois todos os demais atingiram percentuais de acerto em torno de $75,0 \%$ a $100,0 \%$.

IDENTIFICAÇÃO DE FONEMA INICIAL (F2)

Ocupando a segunda posição na escala apresentada, a Identificação de fonema inicial (F2) $(75,0 \%)$, a despeito de ser uma habilidade desenvolvida pela maioria dos indivíduos testados, realizou-se de forma bastante laboriosa pelo Sujeito 17 (0\%). Para os Sujeitos $16(25,0 \%)$ e 9, 10 , 15 e $19(50,0 \%)$ ela está em fase de desenvolvimento.

\section{IDENTIFICAÇÃO DE FONEMA FINAL (F3)}

A Identificação de fonema final (F3) mostrou-se difícil para mais da metade dos sujeitos testados (16 ao todo): Sujeitos 8, 19 e 20 (0,0\% de acerto), Sujeitos 2, 12, 14, e 21 (25,0\% de acerto), e Sujeitos 3, 4, 9, 10 16, 17, 18, 22 e 23 (50,0\% de acerto).

EXCLUSÃO (F4)

Os percentuais apresentados a seguir evidenciam que a Exclusão representou uma tarefa também difícil para doze dos sujeitos testados, mais da metade, portanto. Foram eles: Sujeitos 15, 17, 20 e 21 (0,0\%); Sujeitos 3, 4, 5 e 10 (16,7\%); e Sujeitos 8, 9, 14 e 22 (33,3\%). Os percentuais revelam que a Exclusão apresenta o status de: a) ainda não desenvolvida (4 sujeitos); e b) em início de desenvolvimento (8 sujeitos).

SÍNTESE (F5)

O desempenho dos vinte e três sujeitos na tarefa de Síntese (F5) mostrou que, praticamente, metade deles, dez ao todo, apresentou dificuldades para executar essa tarefa, a saber: Sujeitos 3, 9, 14, 15, 19 e 20 (50,0\% de acerto); Sujeitos 12 e 13 (0,0\%); e Sujeitos 16 e 21 (25,0\%). Os demais já desenvolveram essa habilidade, tendo em vista que seus percentuais de acerto giraram em torno de $75,0 \%$ a $100,0 \%$.

SEGMENTAÇÃO (F6)

Segunda tarefa mais difícil de ser executada, a Segmentação apresentou os seguintes escores: Sujeitos 3, 5, 7, 10, 12, 14, 16, 17, 20, 21 (0,0\% de acerto); Sujeitos 2, 11, 13 (25,0\%); Sujeitos 6, 9, 15, 19, 23 (50,0\%), ou seja, dos vinte e três escolares testados, dez ainda não desenvolveram essa habilidade, três estão em fase inicial de desenvolvimento, e cinco encontramse na "metade do caminho". Apenas cinco sujeitos $(1,4,8,18$ e 22) atingiram percentuais de $75,0 \%$ a $100,0 \%$ de acerto.

TRANSPOSIÇÃO (F7) 
A transposição mostrou-se difícil de ser executada pela grande maioria dos indivíduos investigados: Sujeitos 3, 4, 5, 7, 8, 10, 13, 14, 15, 16, 17, 18 e 22 (0,0\% de acerto); Sujeitos 6, 9, 11, 20 , e $23(25,0 \%)$; e Sujeito $2(50,0 \%)$. Esses números revelam que doze escolares ainda não iniciaram o desenvolvimento dessa habilidade metafonológica, quatro encontram-se em fase inicial de desenvolvimento, e um percorreu metade desse percurso. Dos vinte e três sujeitos submetidos ao teste, apenas três obtiveram acertos em torno de 75,0\% a 100,0\% (Sujeitos 1, 12 e 19), o que evidencia ser a Transposição fonêmica uma habilidade ainda não consolidada.

Durante a execução das tarefas de consciência fonológica, observou-se o emprego de estratégias linguísticas pelos sujeitos, a fim de acertarem as atividades propostas. $\mathrm{Na}$ próxima seção, de cunho qualitativo, serão apresentadas as estratégias linguísticas identificadas neste estudo, assim como alguns exemplos para ilustrá-las.

\subsection{ESTRATÉGIAS LINGUÍSTICAS}

O termo estratégias linguísticas está sendo aqui utilizado como as maneiras por meio das quais os sujeitos procuram obter êxito nas tarefas propostas pelo examinador. O presente estudo identificou algumas estratégias linguísticas, a exemplo de Repetição da $1^{a}$ opção, Repetição da $3^{a}$ opção, Associação Semântica, Associação fonológica, entre outras.

1. Repetição da $1^{\mathrm{a}}$ opção: dado um estímulo e três opções, sendo apenas uma delas a correta, o sujeito opta, equivocadamente, pela $1^{\text {a }}$ opção. Exemplo: "Que desenho é este"?(CABIDE). Agora eu vou dizer 3 palavras. Qual delas começa como 'CABIDE'? BANDEIRA-PALITO-CARROÇA. Resposta esperada: CARROÇA Resposta dada: BANDEIRA.

2. Repetição da $3^{\mathrm{a}}$ opção: dado um estímulo e três opções, sendo apenas uma delas a correta, o sujeito opta, equivocadamente, pela $3^{\text {a }}$ opção. Exemplo: "Que desenho é este? (DEDO). Agora eu vou dizer três palavras. Uma delas começa com o mesmo som da palavra 'DEDO'. Descobre qual é a palavra: DOCE-SAPO-LINHA. Resposta esperada: DOCE. Resposta dada: LINHA.

3. Associação semântica: estratégia usada quando a resposta dada baseia-se em critérios de significação. Exemplo: "Que desenho é este? (RATO). Que outra palavra termina ou rima como RATO? Resposta esperada (possibilidades): MATO, PATO, GATO. Resposta dada: TATU. .

4. Associação fonológica: situação em que a resposta fornecida, de algum modo, apresenta semelhanças fonológicas com o estímulo apresentado. Exemplo: "Eu vou dizer uns sons e vocês vão descobrir que palavra eles formam: M-A-L-A '[m] [a] [1] [a]. Resposta esperada: MALA [mala]. Resposta dada: ALANA.

As estratégias Repetição da $1^{a}$ opção e Repetição da $3^{a}$ opção foram empregadas em tarefas de identificação, ou seja, quando a habilidade envolvida é identificar, os sujeitos tendem a utilizar os extremos $\left(1^{\mathrm{a}}\right.$ ou $\left.3^{\mathrm{a}}\right)$ das opções dadas, provavelmente em virtude de os extremos serem mais facilmente armazenados na memória e, por isso mesmo, tomados como alternativas corretas. Com relação a esse procedimento, vale salientar que Fiori (2008) aborda os fenômenos denominados efeito da primazia e efeito da recência, ao tratar da diferença entre as memórias de curto prazo e de longo prazo.

A autora exemplifica esses fenômenos dizendo que, se for dada uma lista de palavras a uma pessoa e pedido a ela que repita o maior número possível de palavras, a tendência é que ela 
se lembre das primeiras (efeito de primazia) e das últimas (efeito de recência), enquanto que as do meio tendem a ser esquecidas.

A Associação semântica foi adotada em três tarefas: Produção de rima, Síntese (fonêmica) e Identificação de fonema final. Vale mencionar algumas curiosidades com relação à Produção de rima.

Esta tarefa requer que o sujeito faça uma busca em seu léxico mental, de modo a encontrar palavras que rimem com os estímulos apresentados pelo examinador. Assim, dado o estímulo RATO, por exemplo, alguns sujeitos deram como resposta formas como RATOEIRA (Sujeito 19) e ROUPA (Sujeito 12). Esta última, provavelmente, decorreu da associação de significado que o sujeito estabeleceu entre RATO e ROUPA, ambas presentes no trava-línguas "O rato roeu a roupa do rei".

A Associação fonológica restringiu-se à Síntese (fonêmica). Vale observar que a Associação fonológica pode decorrer de semelhança sonora compartilhada entre um ou mais segmentos, a exemplo da resposta ALANA (Sujeito 16) como sendo o resultado da síntese de MA-L-A. Neste caso, ALANA e M-A-L-A compartilham três segmentos. Outros exemplos são

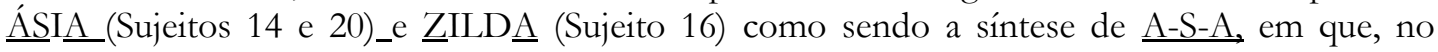
primeiro, há compartilhamento de três segmentos e, no segundo, de dois.

Feitas as considerações acerca das estratégias identificadas nesse estudo, vale ressaltar que outras pesquisas também documentam o emprego de estratégias linguísticas pelos informantes.

Cerqueira (2016) identifica o emprego de dezesseis estratégias linguísticas, sobretudo as de Associação fonológica, Repetição do estímulo e Repetição da $3^{a}$ opção.

Santana (2016) registra a utilização de dezoito estratégias linguísticas, sobretudo as de Associação Fonológica, Repetição da $1^{a}$ opção e Silabificação.

Guedes (2009), ao investigar a consciência fonológica de crianças em períodos pré e pós alfabetização, a partir de um teste por ela elaborado, identificou o emprego de estratégias, denominadas Semânticas, Sonoras, Repetição da palavra-alvo, entre outras.

As estratégias semânticas foram observadas quando as respostas dos sujeitos baseavamse em critérios de significação. Exemplo: solicitada a produzir uma palavra com fonema inicial

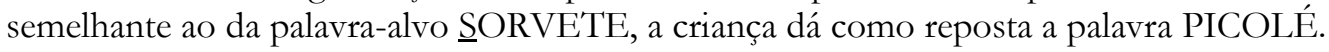

As estratégias sonoras foram observadas quando as respostas dos sujeitos estabeleciam alguma semelhança fonológica com as da palavra-alvo. Exemplo: solicitado a dizer uma palavra

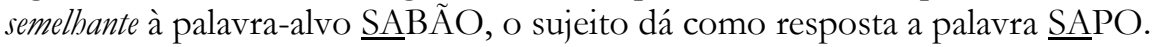

Note-se que o critério adotado pela criança foi a semelhança sonora entre a sílaba inicial da palavra-alvo e a da palavra dada como resposta: SA. Vale assinalar que o examinador deixa o sujeito livre para interpretar o que seria exatamente essa semelhança, justamente com o objetivo de verificar que critério seria adotado na resposta. Como pode ser visto, a criança, nesse caso, lançou mão da estratégia semelhança sonora entre sílabas iniciais.

A Repetição da palavra-alvo foi documentada quando o sujeito repetia a palavra-alvo fornecida pelo examinador. Exemplo: solicitado a dizer uma palavra semelhante à palavra-alvo CADEIRA, o sujeito dá como resposta CADEIRA.

Vale salientar que, a despeito das diferenças entre o estudo de Guedes (2009) e o que foi aqui conduzido, é possível se estabelecer um paralelo entre eles, pois o que Guedes denomina estratégias Semântica, Sonora e Repetição da palavra-alvo, corresponde, de certo modo, ao que, no presente estudo, denominou-se Associação Semântica, Associação Fonológica e Repetição do estímulo, respectivamente. 
Uma outra observação a ser feita é que, independentemente de os sujeitos serem disléxicos ou não, a utilização de estratégias linguísticas para solucionar tarefas de consciência fonológica mostrou-se comum entre eles.

\section{CONCLUSÃO}

O estudo apresentado teve como objetivo principal a investigação do desempenho de alunos disléxicos em tarefas de consciência fonológica.

Os resultados indicaram que os sujeitos investigados, conquanto já tenham sido alfabetizados e, portanto, iniciado o processo de aprendizagem da leitura e da escrita, ainda não consolidaram plenamente a consciência fonológica. Considerando a relação de reciprocidade entre consciência fonológica e aprendizagem da lectoescrita, e tendo em vista que a dislexia caracterizase, justamente, como um transtorno de aprendizagem da leitura (e da escrita), aventa-se a possibilidade de que a não consolidação da consciência fonológica da amostra em questão ocorra, em parte, por conta do quadro de dislexia. Os resultados mostram-se, assim, compatíveis com as abordagens teóricas adotadas nesse estudo.

Quanto aos níveis, observou-se um melhor desempenho dos sujeitos no nível da sílaba do que no nível do fonema, corroborando o previsto na literatura de ser a unidade sílaba mais perceptível, e mais fácil, portanto, do que a unidade fonema.

No nível da sílaba, a tarefa de execução mais fácil foi a Segmentação (S2); a mais difícil, a Produção de rima (S7). As habilidades consolidadas foram Segmentação (S2), Síntese (S1), Produção de palavra com sílaba dada (S5), Identificação de sílaba inicial (S3) e Identificação de rima (S4), enquanto que as não consolidadas foram Exclusão (S8), Transposição (S9), Identificação de sílaba medial (S6) e Produção de rima (S7).

Esses resultados corroboram a concepção de que a consciência fonológica não é monolítica, e de que ela se desenvolve em um continuum. Além disso, esses achados reforçam a relação de reciprocidade entre consciência fonológica e aprendizagem da leitura e da escrita, visto que há habilidades ainda não consolidadas e, assim, muito provavelmente, mais dependentes dessa aprendizagem, sobretudo quando se leva em consideração que a amostra é composta por indivíduos disléxicos.

Com base na amostra investigada, ratificou-se a ideia reportada na literatura de que disléxicos exibem dificuldades para processar informações fonológicas, sobretudo para executar tarefas de consciência fonológica. Ao que tudo indica, então, quanto mais precisas as representações fonológicas em um nível cognitivo, mais facilmente as tarefas de consciência fonológicas são executadas; quanto menos precisas, mais dificuldades tendem a aparecer.

Mais uma vez, vale salientar, esses resultados reforçam a concepção de que a consciência fonológica apresenta uma estrutura hierárquica, na medida em que as habilidades linguísticas investigadas corresponderam a diferentes pontos na escala apresentada.

Além disso, observou-se que, no enfretamento das dificuldades para executar as tarefas metafonológicas, os sujeitos lançaram mão de estratégias linguísticas, cujo emprego, vale ressaltar, parece não se restringir a indivíduos com diagnóstico de dislexia, tendo em vista que outras pesquisas envolvendo normoleitores, também registram o uso de estratégias durante a execução de tarefas de consciência fonológica. $\mathrm{O}$ fato sugere que as diferenças linguísticas entre disléxicos e não disléxicos são mais de cunho quantitativo do que qualitativo, o que demanda novas pesquisas sobre esse tema. 
Outro aspecto a ser ressaltado diz respeito às discrepâncias entre os graus de dificuldade elencados no CONFIAS e aqueles identificados no estudo aqui conduzido, ficando, desde já, a sugestão de futuras pesquisas acerca desse tema.

Ademais, o presente estudo abre caminhos para o desenvolvimento de outras pesquisas envolvendo consciência fonológica e dislexia. A seguir, algumas sugestões: a) investigar se as estratégias aqui identificadas também se manifestam na escrita de disléxicos; b) comparar estratégias linguísticas empregadas por sujeitos disléxicos e não disléxicos em tarefas de consciência fonológica; c) analisar, longitudinalmente, o desempenho de sujeitos disléxicos e não disléxicos, em tarefas de consciência fonológica, d) investigar, longitudinalmente, se o tipo de estratégia linguística muda com o passar dos anos; e e) elaborar novos testes que avaliem a consciência fonológica, tomando como base as características fonológicas do português brasileiro.

\section{REFERÊNCIAS}

ANNALS OF DYSLEXIA, Baltimore, v. 53, p. 01-14, 2003.

BRYANT, Peter e BRADLEY, Linnette. Dificulties in auditory organization as a possible cause of reading backwardness. Nature, 271, p. 746-747, 1978.

BRYANT, Peter e BRADLEY, L. Problemas de leitura na crianç. Porto Alegre: Artes Médicas, 1987. CAPOVILLA, Alessandra G.S. e CAPOVILLA, Fernando César. Problemas de leitura e escrita. Como identificar, prevenir e remediar numa abordagem fônica. 2 ed. S. Paulo: Memnon, 2000.

CARDOSO-MARTINS, Cláudia. A habilidade de crianças em idade pré-escolar de identificar uma palavra impressa desconhecida por analogia a uma palavra conhecida. In: CARDOSOMARTINS, Cláudia (organizadora). Consciência fonológica e alfabetização. Petrópolis, Rio de Janeiro: Vozes, 1995.

CARVALHO, Wilson Júnior de Araújo. O desenvolvimento da consciência fonológica: da sensibilidade à consciência plena das unidades fonológicas. Tese de doutorado. Instituto de Letras da Universidade Federal da Bahia. Salvador, 2003.

CERQUEIRA, Juciana Santos. Consciência fonológica e aquisição da escrita: perfil dos sujeitos do Ensino Fundamental I em Euclides da Cunha-BA. Dissertação de mestrado. Departamento de Letras e Artes da Universidade Estadual de Feira de Santana. Feira de Santana, Bahia, 2016.

FREITAS, Gabriela Castro Menezes de. Sobre Consciência Fonológica. In: LAMPRECHT, Regina Ritter et al. Aquisişão Fonológica do Português. Perfil de Desenvolvimento e Subsídio Para Terapia. Porto Alegre: Artmed, 2004

GOUGH, P.; LARSON, K.; YOPP, H. A estrutura da consciência fonológica. In: CARDOSOMARTINS, Cláudia (organizadora). Consciência fonológica e alfabetizạ̧ão. Petrópolis, Rio de Janeiro: Vozes, 1995.

GRUNWELL, Pamela. Clinical Phonology. London: Croom Helm, 1982.

HEILMAN, KM. Ann Neurol; 39: 407-12, 1996.

HINSHELWOOD, James. A case of dyslexia: a peculiar form of word-blindness. The Lancet, London, v. 2, p. 1451-1454, 1896.

INGRAM, David. Phonological disability in children. Londres: Edward Arnold, 1976. 
Phonological development: production. In: FLETCHER, P. \& GARMAN, M. (orgs). Language acquisition. 2. ed. London: Edward Arnold, 1986.

LAMPRECHT, Regina Ritter et al. Aquisição fonológica do português: perfil de desenvolvimento e subsídios para terapia. Porto Alegre: Artmed, 2004.

MOOJEN, Sônia, LAMPRECHT, Regina et alii. CONFLAS. Consciência fonológica: instrumento de avaliação seqüencial. São Paulo: Casa do Psicólogo, 2003.

MORAIS, J.; BERTELSON, P.; CARY, L.; ALEGRIA, J. Literacy training and speech segmentation. Cognition, n. 24, p. 45-64, 1986.

MORAIS, Antonio Manuel Pamplona de. A relação entre a consciência fonológica e as dificuldades de leitura. São Paulo: Vetor, 1997.

MORGAN, Pringle. A case of congenital word-blindness. The British Medical Journal. London, v.2, p. $1378-1379,1896$.

ORTON, S.T. Word-blind in school children. Archives of Neurology and Psychiatry, v.14, n.5, p.582615, November, 1925.

PENNINGTON, Bruce F.Toward an integrated understanding of dyslexia: Genetic, neurological and cognitive mechanisms. Development and psychopatology, 11, p.629-654, 1999.

PEPE, Vera Pedreira dos Santos. Dislexia e processos fonológicos. Tese de doutorado. Instituto de Letras da Universidade Federal da Bahia. Salvador, 2010.

PERFETTI, C.; BECK, I.; BALL, L.; HUGHES, C. Phonemic knowledge and learning to read are reciprocal: a longitudinal study of first grade children. Merril-Palmer Quarterly, n.33, p. 283-319, 1987.

PESTUN, Magda Solange Vanzo. Consciência fonológica no início da escolarização e o desempenho ulterior em leitura e escrita: estudo correlacional. Estudos de Psicologia 10(3), p. 407412, 2005.

READ, C.; YUN-FEI, Z.; HONG-YIN, N.; BAO-QING, D. The ability to manipulate speech sounds depends on knowing alphabetic spelling. Cognition, n 24, p. 31-44, 1986.

SHAYWITZ, Sally. Entendendo a dislexia: um novo e completo programa para todos os níveis de problemas de leitura. Trad. Vinícius Figueira. Porto Alegre: Artmed, 2006.

SNOWLING, Margaret e STACKHOUSE, Joy. Dislexia, fala e linguagem: um manual do profissional. Porto Alegre: Artmed, 2004.

SNOWLING, Margaret. Dislexia. 2. ed. S. Paulo: Santos, 2004.

STANOVICH, Keith E. e SIEGEL, Linda S. Phenotypic performance profile of children with reading disabilities: A regression-based test of the Phonological -Core variable-difference model. Journal of Educational Psychology, v. 86, n.1, p.24-52, 1994.

STANOVICH, Keith E. Annotation: Does dyslexia exist? Journal of child Psychology and Psychiatry, v. 35, n.4, p. 579-595, 1994.

TEIXEIRA, Elizabeth Reis. Perfil do desenvolvimento fonológico do português (P.D.F.P.). In: Revista Estudos, Salvador, n. 12, p. 225-237, 1991. 
VELLUTINO, F.R. Dyslexia. Scientific American, v. 256, p. 20-27, March, 1987.

Recebido em: 02/05/2017

Aprovado em: 08/08/2017

Publicado em: 01/12/2017 